\title{
Thomas Maciag In praise of an open mind
}

1. n my office, I have a painting. It depicts a waterway in Venice that is flanked by a row of eight buildings that recede diagonally from the foreground on the right to the background on the left. In the middle distance, a lone boatman plies his way inward along the canal. Blue- or red-and-white barber pole moorings demarcate the water's edge. Each edifice rising from the water is architecturally detailed, with its own unique collection of pitched roofs, porticos, balustrades, niches, and statuettes. Rows of doors, windows, and balconies punctuate each façade. The colors are bold - a saturated reddish-brown invests each structure, setting it apart from the sky's ethereal blue and the water's murky gray. There is a strong sense of perspective in this picture, but the eye is drawn to a vanishing point that lies not within the watercolor image itself but off to the left, beyond the confines of the frame. The artist was Tom Maciag, who died on March 8, 2004.

Tom was born November 19, 1946 in Bayonne, New Jersey. He served in the US Army Medical Corps (1969-1971) and then received a Ph.D. in Molecular Biology and Biochemistry from the University of Pennsylvania (1975). After a year of postdoctoral work at Penn, he became a senior research investigator at Collaborative Research Inc. in Waltham, Massachusetts (1976-1979), and then a research fellow in Medicine (1979-1980) and assistant professor of Pathology at Harvard Medical School (1980-1983). He returned to the biotech arena as director of Cell Biology at the Revlon Biotechnology Research Center in Rockville, Maryland (1983-1986), which was acquired by Rorer Pharmaceuticals in 1985. He was invited to lead the Department of Molecular Biology at the Jerome H. Holland Laboratory for Biomedical Sciences at the American Red Cross in 1986, a post he held for the next 11 years. In 1997, he was recruited to establish the Center for Molecular Medicine at Maine Medical Center Research Institute, where he remained for the next seven years.

A gifted scientist, Tom contributed a remarkable series of new concepts to the field of developmental vascular biology. In 1979, he discovered an activity in bovine hypothalamus that was mitogenic for human umbilical vein endothelial cells and distinct from the previously described bovine brain growth factor, later known as basic fibroblast growth factor (bFGF, FGF-2) (1). He was the first to demonstrate that "endothelial cell growth factor," subsequently dubbed acidic FGF or FGF-1, supported the long-term propagation of human endothelial cells in culture, thus laying the groundwork for dozens of inves-

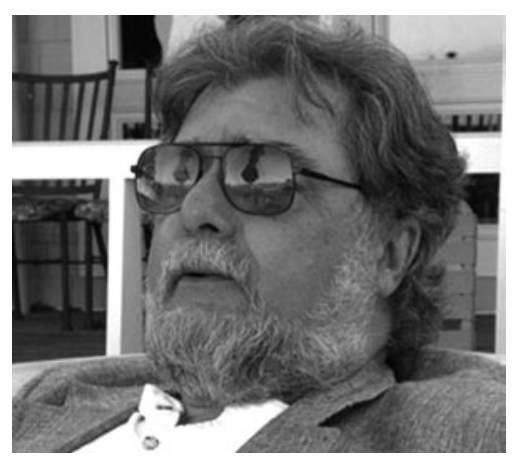

tigators who followed (2-4). He completed the biochemical characterization of FGF-1 (5-7), delineated its heparin-binding properties (8-10), pointed out its chemotactic characteristics (11), and identified its high affinity tyrosine kinase receptor $(12,13)$. His laboratory was instrumental in the cloning of the FGF-1 cDNA (14), and he was also first to demonstrate the ability of FGF-1 to support neoangiogenesis in vivo (15). These studies (16), carried out with Michael Stemerman, Robert Weinstein, Gayle Hoover, Robert Friesel, Wilson Burgess, and Todd Rosengart, prompted research that would reveal the crucial role of FGFs in angiogenesis, wound healing, and atherogenesis.

From this detailed framework of FGF biology, Tom began his most visionary set of experiments. In the 1990s, he and his group, including Anthony Jackson, Francesca Tarantini, Carla Mouta Carreira, Matteo Landriscina, Igor Prudovsky, Raffaella Soldi, Anna Mandinova, and Lazar Mandinov, reported that FGF-1, which lacks a classical signal sequence for secretion, was released from cultured cells in response to heat shock (17). He subsequently char- acterized an FGF-1 "release complex" that requires cysteine-mediated FGF-1 homodimerization in response to copper oxidation (18-20), interaction with phosphatidyl serine (21), binding to the extravesicular domain of synaptotagmin-1 $(22,23)$, and association with S100A13, a member of the S100 family of calcium-regulated proteins (24-26). He developed an animal model to show the ability of an oral copper chelator to reduce neointimal thickening following aortic balloon injury in the rat (27), and he postulated a "molten globule" model of FGF-1 release whereby a polypeptide traverses the plasma membrane in a partially unfolded high energy conformation (28). These experiments suggested that cells can respond to metabolic stress by releasing bioactive mediators that may stimulate mitosis, recruit inflammatory cells, or reorganize the extracellular milieu.

Tom's work also defined the interrelationships among the inflammatory response, atherogenesis, and angiogenesis. With Timothy Hla, he showed that cyclooxygenase and endothelial differentiation gene (EGD-1) are immediate-early genes induced by interleukin-1 or phorbol ester in the endothelial cell (29-32). With Elizabeth and Gary Nabel, he showed that recombinant FGF-1 promotes intimal hyperplasia and angiogenesis in arteries in vivo (33). With Ann Zimrin, Radiana Trifonova, Deena Small, and Lucy Liaw, he showed that the notch-jagged signaling system inhibits FGF-1-dependent cellular transformation (34-37). These studies identified new scenarios for rational drug design.

In the end, Tom Maciag's creativity transcended his art and permeated his science. In both disciplines, he sought order in the midst of apparent chaos. He celebrated ideas - the new, the surprising, the iconoclastic. But, though he thought "outside the box," he maintained a true perspective. In his life and work, Tom inspired us to look beyond the landscape of the familiar toward something more distant and unexplored. He will be greatly missed.

\section{Katherine A. Hajjar}

Weill Medical College of Cornell University khajjar@med.cornell.edu 
1. Maciag, T., Cerundolo, J., Ilsley, S., Kelley, P.R., and Forand, R. 1979. An endothelial cell growth factor from bovine hypothalamus: identification and partial characterization. Proc. Natl. Acad. Sci. U. S. A 76:5674-5678

2. Maciag, T., Hoover, G.A., Stemerman, M.B., and Weinstein, R. 1981. Serial propagation of human endothelial cell in vitro. J. Cell Biol. 91:420-426.

3. Maciag, T., Kadish, J., Wilkins, L., Stemerman, M.B., and Weinstein, R. 1982. Organizational behavior of human umbilical vein endothelial cells. J. Cell Biol. 94:511-520.

4. Lemmon, S.K., et al. 1982. Bovine fibroblast growth factor: comparison of brain and pituitary. J. Cell Biol. 95:162-169.

5. Burgess, W., Mehlman, T., Friesel, R., Johnson, W.V., and Maciag, T. 1985. Multiple forms of endothelial cell growth factor. Rapid isolation and biological and chemical characterization. J. Biol. Chem. 260:11389-11392.

6. Burgess, W., Mehlman, T., Marshak, D.R., Fraser, B.A., and Maciag, T. 1986. Structural evidence that endothelial cell growth factor beta is the precursor of both endothelial cell growth factor alpha and acidic fibroblast growth factor. Proc. Natl. Acad. Sci. U. S. A. 83:7216-7220.

7. Maciag, T., Hoover, G.A., and Weinstein, R. 1982. High and low molecular weight forms of endothelial cell growth factor. J. Biol. Chem. 257:5333-5336.

8. Maciag, T., Mehlman, T., Friesel, R., and Schreiber, A.B. 1984. Heparin binds to endothelial cell growth factor, the principal endothelial cell mitogen in bovine brain. Science. 225:932-935.

9. Schreiber, A.B., et al. 1985. Interaction of endothelial cell growth factor with heparin: characterization by receptor and antibody recognition. Proc. Natl. Acad. Sci. U. S. A. 82:6138-6142.

10. Rosengart, T.K., Johnson, W.V., Friesel, R., Clark, R., and Maciag, T. 1988. Heparin protects heparin-binding growth factor- 1 from proteolytic inactivation in vitro. Biochem. Biophys. Res. Commun. 152:432-440.

11. Terranova, V.P., et al. 1985. Human endothelial cells are chemotactic to endothelial cell growth factor and heparin. J. Cell Biol. 101:2330-2334.

12. Friesel, R., Burgess, W., Mehlman, T., and Maciag, T. 1986. The characterization of the receptor for endothelial cell growth factor by covalent ligand attachment. J. Biol. Chem. 261:7581-7584.

13. Friesel, R., and Maciag, T. 1988. Internalization and degradation of heparin binding growth factor- 1 by endothelial cells. Biochem. Biophys. Res. Commun. 151:957-964.

14. Jaye, M., et al. 1986. Human endothelial cell growth factor: cloning, nucleotide sequence, and chromosome localization. Science. 233:541-545.

15. Thompson, J.R., et al. 1988. Site-directed neovessel formation in vivo. Science. 241:1349-1352

16. Burgess, W., and Maciag, T. 1989. The heparinbinding (fibroblast) growth factor family of proteins. Annu. Rev. Biochem. 58:575-606.

17. Jackson, A., et al. 1992. Heat shock induces the release of fibroblast growth factor 1 from NIH 3T3 cells. Proc. Natl. Acad. Sci. U. S. A. 89:10691-10695.

18. Jackson, A., Tarantini, F., Gamble, S., Friedman, S., and Maciag, T. 1995. The release of fibroblast growth factor- 1 from NIH $3 \mathrm{~T} 3$ cells in response to temperature involves the function of cysteine residues. J. Biol. Chem. 270:33-36.

19. Landriscina, M., et al. 2001. Copper induces the assembly of a multiprotein aggregate implicated in the release of fibroblast growth factor 1 in response to stress. J. Biol. Chem. 276:25549-25557.

20. Engleka, K.A., and Maciag, T. 1992. Inactivation of human fibroblast growth factor-1 (FGF-1) activity by interaction with copper ions involves FGF-1 dimer formation induced by copper-catalyzed oxidation. J. Biol. Chem. 267:11307-11315.

21. Tarantini, F., Gamble, S., Jackson, A., and Maciag, T. 1995. The cysteine residue responsible for the release of fibroblast growth factor- 1 residues in a domain independent of the domain for phosphatidylserine binding. J. Biol. Chem. 270:29039-29042.

22. Tarantini, F., et al. 1998. The extravesicular domain of synaptotagmin-1 is released with the latent fibroblast growth factor-1 homodimer in response to heat shock. J. Biol. Chem. 273:22209-22216.

23. LaVallee, T., et al. 1998. Synaptotagmin-1 is required for fibroblast growth factor-1 release. J. Biol. Chem. 273:22217-22223.

24. Mouta Carreira, C., et al. 1998. S100A13 is involved in the regulation of fibroblast growth factor- 1 and p40 synaptotagmin-1 release in vitro. J. Biol. Chem. 273:22224-22231.

25. Landriscina, M., et al. 2001. S100A13 participates in the release of fibroblast growth factor 1 in response to heat shock in vitro. J. Biol. Chem.
276:22544-22552.

26. Prudovsky, I., et al. 2002. The intracellular translocation of the components of the fibroblast growth factor 1 release complex precedes their assembly prior to export. J. Cell Biol. 158:201-208.

27. Mandinov, L., et al. 2003. Copper chelation represses the vascular response to injury. Proc. Natl. Acad. Sci. U. S. A. 100:6700-6705.

28. Prudovsky, I., et al. 2003. The non-classical export routes: FGF1 and IL-1a point the way. J. Cell Sci. 116:4871-4881.

29. Hla, T., and Maciag, T. 1990. Isolation of immediate-early differentiation mRNAs by enzymatic amplification of subtracted cDNA from human endothelial cells. Biochem. Biophys. Res. Commun. 167:637-643.

30. Maier, J.A., Hla, T., and Maciag, T. 1990. Cyclooxygenase is an immediate-early gene induced by interleukin-1 in human endothelial cells. J. Biol. Chem. 265:10805-10858.

31. Hla, T., and Maciag, T. 1991. Cyclooxygenase gene expression is down-regulated by heparin-binding (acidic fibroblast) growth factor-1 in human endothelial cells. J. Biol. Chem. 266:24059-24063.

32. Hla, T., and Maciag, T. 1990. An abundant transcript induced in differentiating human endothelial cells encodes a polypeptide with structural similarities to G-protein-coupled receptors. J. Biol. Chem. 265:9308-9313.

33. Nabel, E.G., et al. 1993. Recombinant fibroblast growth factor-1 promotes intimal hyperplasia and angiogenesis in arteries in vivo. Nature. 362:844-846

34. Zimrin, A.B., et al. 1996. An antisense oligonucleotide to the notch ligand jagged enhances fibroblast growth factor-induced angiogenesis in vitro. J. Biol. Chem. 271:32499-32502.

35. Wong, M.K., et al. 2000. A non-transmembrane form of Jagged-1 regulates the formation of matrix-dependent chord-like structures. Biochem. Biophys. Res. Commun. 268:853-859.

36. Small, D., et al. 2003. Notch activation suppresses fibroblast growth factor-dependent cellular transformation. J. Biol. Chem. 278:16405-16413.

37. Trifonova, R., et al. 2004. The non-transmembrane form of Delta1, but not of jagged1, induces normal migratory behavior accompanied by fibroblast growth factor receptor 1-independent transformation. J. Biol. Chem. 279: 13285-13288. 